\title{
Combined Diagnostic Value of Both CT and MRI in Pre-Operative Evaluation of Cochlear Implant Patients
}

\author{
AYA M. ADLY GABR, M.Sc.*; MOHAMMED M. DAWOUD, M.D.*; MOHAMAD H.A. HAMAD, M.D.** and \\ MOHAMAD F. SHERIF, M.D.*
}

The Departments of Radio-Diagnosis \& Medical Imaging* and Otorhinolaryngology**, Faculty of Medicine, Tanta University

\begin{abstract}
Background: Cochlear implantation is considered an acceptable treatment for severe to profound sensorineural hearing loss with normal cochlea and cochlear nerve. CT is the best modality for evaluation of bony labyrinth and MRI is the best modality to evaluate membranous labyrinth so combined CT and MRI is mandatory for preoperative evaluation for cochlear implantation, radiologist should be familial with absolute and relative contraindication of cochlear implantation.
\end{abstract}

Aim of Study: The aim of this study is to evaluate the role of HRCT and MRI in pre-operative assessment of cochlear implantation candidates.

Patients and Methods: Our study included 60 patients (120 ears) 39 of them were males while 21 were females. The age of our selected patents ranged from 2 to 60 years with a mean of 15.8 years most of them were in pediatric age group 2-10 years representing $60 \%$. The present study included patients with bilateral profound sensory neural hearing loss, minimum age of eligibility is 1 year, both sexes will be included. We excluded pediatric age group $>1$ year. All patients were subjected to the clinical evaluation. Computed Tomography (CT), all CT studies (60 figs) were obtained using a 320-row multidetector CT scanner (Aquilion One Toshiba Medical Systems, Otawara, Japan) installed in Tanta University Educational Hospital.Magnetic Resonance Imaging (MRI), all MRI studies (60 figs) were obtained using a closed MRI machine (General Electric SIGNA) HS (high speed) with magnets of intensity field $1.5 \mathrm{~T}$.

Results: Combined HRCT and MRI revealed a normal appearance of the labyrinth and internal auditory canal in 44 (88 ears) patients (73\%). In 16 (32 ears) patients (26\%) had abnormalities of the labyrinth; 10 patients $(16 \%)$ of them had congenital anomalies and 6 patients $(10 \%)$ had acquired Sensoneural Hearing Loss (SNHL). Ten patients (16\%) had congenital abnormalities of inner ear bilaterally; absent cochlea $(\mathrm{n}=3)$ represented $5 \%$, IP type $\mathrm{I}(\mathrm{n}=2)$ represented 3\%, IP type II $(n=4)$ represented $6 \%$, common cavity $(n=1)$ represent about $2 \%$, absent vestibule $(\mathrm{n}=3)$ represented $5 \%$, dilated vestibule $(n=6)$ represented $10 \%$, dilated vestibular aqueduct $(n=5)$ represented $8 \%$ and dysplastic semicircular canals $(n=4)$

Correspondence to: Dr. Aya M. Adly Gabr,

The Department of Radio-Diagnosis \& Medical Imaging, Faculty of Medicine, Tanta University represented $7 \%$. The cochlear nerve was normal in 57 figs (95\%), while two patients (3\%) had absent nerve, and one patient $(2 \%)$ presented with atrophied cochlear nerve. Narrowed internal auditory canal $(n=3)$ represented $5 \%$. Six patients $(10 \%)$ had acquired sensoneural hearing loss after meningitis, labyrinthitis, otitis media, trauma and sequalae of old age. Calcifications within the cochlea and in the semicircular canals caused by labyrinthitis ossificans $(n=3)$ represented $5 \%$ and otosclerosis $(n=1)$ represented about $2 \%$. In current study, we found 4 ears with narrow IAC and absent vestibulocochlear nerve, 2 ears with narrowed IAC and atrophied small sized vestibulocochlear nerve. In all of them the assessment of VCN were done using 3D MRI.

Conclusion: Combined HRCT and MRI studies are mandatory for evaluation of inner ear, the radiologist must be familiar with imaging findings that absolutely contraindicate implantation (Cochlear aplasia, cochlear nerve aplasia and labyrinthine aplasia), and with those that relatively contraindicate implantation (labyrinthitis ossificans, other inner ear dysplasia) and with other findings that could significantly alter or complicate surgery (hypoplastic mastoid process, facial nerve dehiscence, oto-mastoiditis).

Key Words: CT - MRI-Cochlear implant - Hearing loss.

\section{Introduction}

MORE than 28 million people across the world had some degree of hearing impairment. Cochlear implantation has become an accepted treatment for severe to profound deafness in patients who derive only minimal benefit from conventional amplification [1].

Congenital sensorineural hearing loss arises as a result of abnormalities in the inner ear, the vestib? ulocochlear nerve, or the processing centers of the brain. The abnormality may have a genetic cause or be a sequel of infection or injury at birth; in some figs, no cause is identified [2].

High-resolution Computed Tomography (CT) and Magnetic Resonance (MR) imaging of the temporal bones allow excellent depiction of inner 
ear malformations and are routinely used in the evaluation of pediatric sensorineural hearing loss. CT has always been the preferred imaging modality to delineate the intricate osseous anatomy and malformations of the inner ear, but high-resolution MR imaging is used with increasing frequency to study the membranous labyrinth and eighth cranial nerve (vestibulocochlear nerve) $[\mathbf{3 , 4}]$.

Pre-operative high-resolution CT of the temporal bone allows the additional identification of middle and external ear abnormalities and provides anatomic information that is important for surgical planning. Together, these modalities play a vital role in the pre-operative work-up for cochlear implantation [5]

For optimal interpretation of high-resolution $\mathrm{CT}$ and MR images obtained in children with congenital sensorineural hearing loss, the radiologist must have a comprehensive knowledge of the embryologic development of normal inner ear structures as well as the spectrum of malformations that may be encountered [6]

Cochlear implant is the method of choice in the treatment of deep sensorineural hypoacusis, particularly in patients where conventional amplification devices do not imply noticeable clinical improvement. Imaging findings are crucial in the indication or contraindication for such surgical procedure. In the assessment of the temporal bone [7].

Some criteria such as cochlear nerve aplasia, labyrinthine and/or cochlear aplasia are still considered as absolute contraindications, in spite of studies bringing such criteria into question. Cochlear dysplasias constitute relative contraindications; among them labyrinthitis ossificans is highlighted. Other alterations may be mentioned as complicating agents in the temporal bone assessment, namely, hypoplasia of the mastoid process, aberrant facial nerve, otomastoiditis, otosclerosis, dehiscent jugular bulb, enlarged endolymphatic duct and sac. [7].

\section{Patients and Methods}

This prospective study was carried out upon 60 patients (39 male, 21 female) the age of our selected patents ranged from 2 to 60 years with a mean of 15.8 years most of them were in pediatric age group 2-10 years representing 60\%. They were referred to Diagnostic Radiology and Medical Imaging Department, Tanta University Hospital from ENT Department and presented with hearing loss throughout the period from August 2017 to October 2018. The study approved by Research
Ethics Committee (REC) and informed written consent were obtained from all participants in the study after full explanation of the benefits and risks of the procedure. Privacy \& confidentiality of all patient data were guaranteed. All data provision was monitored and used for scientific purpose only.

Patients with bilateral profound sensory neural hearing loss, with the minimum age of eligibility is 1 year, and both sexes were included. While Paediatric age group $>1$ year were excluded. All patients were subjected to clinical evaluation, Computed Tomography (CT), and Magnetic Resonance Imaging (MRI). All CT studies (60 figs) were obtained using a 320-row multidetector CT scanner (Aquilion One Toshiba Medical Systems, Otawara, Japan) installed in Tanta University Educational Hospital. Patients lied supine with head first. Scout films were taken routinely in all patients. Scanning commenced from the lower margin of external auditory meatus and extended upward to the arcuate eminence of superior semicircular canal, as seen on the lateral topogram. Continuous 0.5$1 \mathrm{~mm}$-thin slices were obtained at $1 \mathrm{~mm}$ interval using ultrahigh algorithm with a scan time of 20 s with a delay of $4 \mathrm{~s}$ at $120 \mathrm{kV}$ tube voltage and 400 $\mathrm{mAs}$ (Milli amber Second). The cochlea, vestibule, three semicircular canals, endolymphatic duct and sac, internal auditory canal, bony and membranous labyrinth were assessed on both 3D MRI and CT exams and rated as pathologic or normal. In 3D MRI, particular attention was given to the visibility of all four nerves in the internal auditory canal as well as abnormal signal intensities within the labyrinth; moreover, the cerebellopontine angle was evaluated for any abnormality.

All MRI studies (60 figs) were obtained using a closed MRI machine (General Electric SIGNA) HS (high speed) with magnets of intensity field 1.5T. The patient is positioned supine with head first. Axial T1 weighted (TR/TE, 500/10ms) with slice thickness $3 \mathrm{~mm}$, gap $1 \mathrm{~mm}$, FOV $32-42 \mathrm{~cm}$ and matrix $256 \times 256$. Axial T2 weighted (TR/TE, $3300 / 100 \mathrm{~ms}$ ) with slice thickness $3 \mathrm{~mm}$, gap $1 \mathrm{~mm}$, FOV $32-42 \mathrm{~cm}$ and matrix $256 \times 256$.

- Sagittal oblique T2 weighted with slice thickness $1-3 \mathrm{~mm}$, gap $1 \mathrm{~mm}$, FOV $40-50 \mathrm{~cm}$ and matrix 256 X 256. Coronal T2 weighted with slice thickness $1-3 \mathrm{~mm}$, gap $1 \mathrm{~mm}$, FOV $40-50 \mathrm{~cm}$ and matrix 256 X 256. MRI 3D reconstruction coronal image is the best choice for the clear delineation of the cochlear turns. We used coronal 3D reconstruction image of the MRI for taking measurement of the cochlea. 


\section{Results}

Our study included 60 patients (120 ears) 39 of them were males while 21 were females. The age of our selected patents ranged from 2 to 60 years with a mean of 15.8 years most of them were in pediatric age group 2-10 years representing $60 \%$. The different age groups are listed in (Table 1).

Table (1): Age and sex distribution in the studied patients ( $n=60$ patients).

\begin{tabular}{|c|c|c|c|c|c|c|}
\hline \multirow{4}{*}{$\begin{array}{l}\text { Age in } \\
\text { years }\end{array}$} & \multicolumn{4}{|c|}{ Sex } & \multirow{2}{*}{\multicolumn{2}{|c|}{ Total }} \\
\hline & \multirow{2}{*}{\multicolumn{2}{|c|}{ Male }} & \multirow{2}{*}{\multicolumn{2}{|c|}{ Female }} & & \\
\hline & & & & & No & $\%$ \\
\hline & No & $\%$ & No & $\%$ & & \\
\hline $2-<10$ & 22 & 36.7 & 14 & 23.3 & 36 & 60 \\
\hline $10-<20$ & 6 & 10 & 3 & 5 & 9 & 15 \\
\hline $20-<30$ & 4 & 6.7 & 2 & 3.3 & 6 & 10 \\
\hline $30-<40$ & 2 & 3.3 & 1 & 1.7 & 3 & 5 \\
\hline $40-<50$ & 3 & 5 & 0 & 0 & 3 & 5 \\
\hline $50-60$ & 2 & 3.3 & 1 & 1.7 & 3 & 5 \\
\hline Total & 39 & 65 & 21 & 35 & 60 & 100 \\
\hline
\end{tabular}

Combined HRCT and MRI revealed a normal appearance of the labyrinth and internal auditory canal in 44 (88 ears) patients (73\%). In 16 (32 ears) patients $(26 \%)$ had abnormalities of the labyrinth; 10 patients $(16 \%)$ of them had congenital anomalies and 6 patients (10\%) had acquired Sensoneural Hearing Loss (SNHL). Ten patients (16\%) had congenital abnormalities of inner ear bilaterally; absent cochlea $(n=3)$ represented $5 \%$, IP type I $(\mathrm{n}=2)$ represented $3 \%$, IP type II $(\mathrm{n}=4)$ represented $6 \%$, common cavity $(\mathrm{n}=1)$ represent about $2 \%$, absent vestibule $(\mathrm{n}=3)$ represented $5 \%$, dilated vestibule $(n=6)$ represented $10 \%$, dilated vestibular aqueduct $(\mathrm{n}=5)$ represented $8 \%$ and dysplastic semicircular canals $(n=4)$ represented $7 \%$. The cochlear nerve was normal in 57 figs $(95 \%)$, while two patients (3\%) had absent nerve, and one patients $(2 \%)$ presented with atrophied cochlear nerve. Narrowed internal auditory canal $(n=3)$ represented $5 \%$. Six patients $(10 \%)$ had acquired sensoneural hearing loss after meningitis, labyrinthitis, otitis media, trauma and sequalae of old age. Calcifications within the cochlea and in the semicircular canals caused by labyrinthitis ossificans $(\mathrm{n}=3)$ represented $5 \%$ and otosclerosis $(\mathrm{n}=1)$ represented about $2 \%$. The above findings are listed in (Table 2).

\section{Cochlear anomalies:}

In 10 patients (17\%), combined MRI and HRCT depicted abnormalities that affected the cochlea on both sides as listed in (Table 3). Absent cochlea detected in 3 patients representing $5 \%$, presented in $\mathrm{CT}$ as absent cochlea and lost normal high signal intensity fluid in cochlea on high resolution T2 MRI. Incomplete Partition (IP) type I detected in 2 patients representing about $3 \%$. HRCT and MRI revealed that cochlea had a cystic appearance and the vestibule is dilated (featureless cochlea and vestibule with characteristic figure of 8). Incomplete Partition (IP) type II (Mondini malformation) detected in 4 patients representing $6 \%$. In HRCT $\&$ MRI the cochlea consists of $1 / 2$ turns, the basal cochlear turn appears normal, but the middle and apical turns coalesce to form a cystic apex. These patients associated with a large endolymphatic sac and an enlarged vestibular aqueduct. Common cavity $(n=1)$ representing $2 \%$ of figs. Cochlea, vestibule \& SCC in HRCT and MRI form common cavity of variable size with featureless cochlea and vestibule.

These findings were listed in (Table 3) and Fig. (1).

Table (2): Spectrum of HRCT and MRI findings.

\begin{tabular}{lcc}
\hline Findings & Number & Percentage \% \\
\hline Absent cochlea. & 3 & 5 \\
IP type I. & 2 & 3 \\
IP type II. & 4 & 6 \\
Common cavity. & 1 & 2 \\
Absent cochlear nerve. & 2 & 3 \\
Atrophied cochlear nerve. & 1 & 2 \\
Absent vestibule. & 3 & 5 \\
Dysplastic dilated vestibule. & 6 & 10 \\
Dilated vestibular aqueduct. & 5 & 8 \\
Dysplastic SSC. & 4 & 7 \\
Narrowed IAC. & 3 & 5 \\
Labyrinthitis ossificans. & 3 & 5 \\
Otosclerosis. & 1 & 2 \\
\hline
\end{tabular}

N.B: One patient could present with multiple MRI findings.

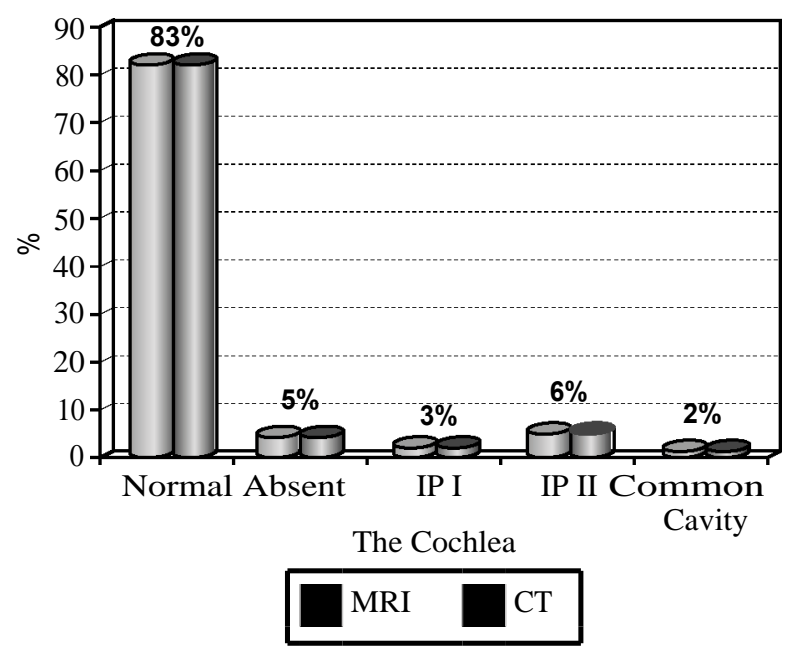

Fig. (1): A graph summarizing MRI and CT findings of involved patients regarding the cochlea. 
Table (3): Summary of MRI and CT findings of cochlear anomalies.

\begin{tabular}{lllll}
\hline \multirow{2}{*}{ The cochlea } & \multicolumn{2}{c}{ CT } & \multicolumn{2}{c}{ MRI } \\
\cline { 2 - 5 } & $\mathrm{N}$ & $\%$ & $\mathrm{~N}$ & $\%$ \\
\hline Normal & 50 & 83 & 50 & 83 \\
Absent & 3 & 5 & 3 & 5 \\
IP I & 2 & 3 & 2 & 3 \\
IP II & 4 & 6 & 4 & 6 \\
Common cavity & 1 & 2 & 1 & 2 \\
\hline
\end{tabular}

\section{Cochlear nerve abnormalities:}

The cochlear nerve was normal in 57 figs (95\%), while two patients (3\%) had absent cochlear nerve and narrowed internal auditory canal while one patient $(2 \%)$ had atrophied cochlear nerve and narrowed internal auditory canal as listed in (Table 4), Fig. (2).

Table (4): Summary of cochlear nerve and internal auditory canal findings.

\begin{tabular}{llll}
\hline Cochlear nerve & IAC & $(\mathrm{n}=)$ & $\%$ \\
\hline Absent & Narrow & 2 & 3 \\
Atrophy & Narrow & 1 & 2 \\
Normal & Normal & 57 & 95 \\
\hline Total & Total & 60 & 100 \\
\hline
\end{tabular}

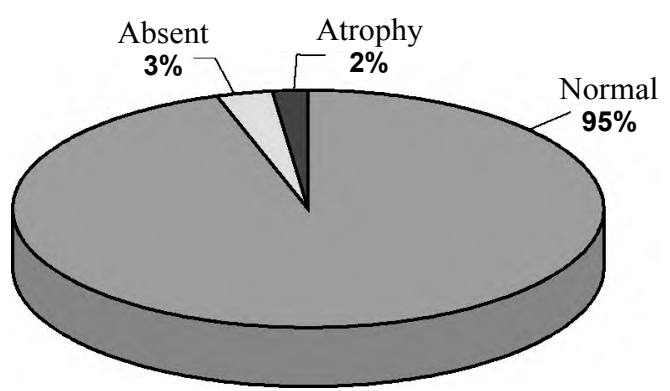

Fig. (2): Summary of cochlear nerve and internal auditory canal findings.

\section{Anomalies:}

Combined MRI and HRCT depicted vestibular abnormalities in 10 patients $(17 \%)$ bilaterally associated with deformed dysplastic semicircular canals. Absent vestibule associated with cochlear aplasia $(n=3)$ representing 5\% with deformed semicircular canals. Incomplete Partition (IP) type I $(n=2)$ representing about 3\%. Incomplete Partition (IP) type II (Mondini malformation) $(\mathrm{n}=4)$ representing $6 \%$. Common cavity $(\mathrm{n}=1)$ representing $2 \%$, no isolated vestibular anomalies reported. These findings were listed in (Table 5).

\section{Vestibular aqueduct abnormalities:}

Combined MRI and HRCT depicted abnormalities that affected the vestibular aqueduct in 5 patients (8\%). 4 patients associated with Incomplete Partition (IP) type II representing 6\%. Isolated dilated vestibular aqueduct $(\mathrm{n}=1)$ representing $2 \%$. In HRCT and MRI revealed dilated vestibular aqueduct (vestibular aqueduct syndrome).

\section{Labyrinthitis ossificans:}

Labyrinthitis ossificans detected in 3 patients representing $5 \%$. Ossification of the basal turns of the cochlea detected in HRCT and in MRI T2 revealed reduced endolymph signal reflected from the cochlear turns.

Table (5): MRI and CT findings of vestibular anomalies.

\begin{tabular}{lllll}
\hline \multirow{2}{*}{ The vestibule } & \multicolumn{2}{c}{ CT } & \multicolumn{2}{c}{ MRI } \\
\cline { 2 - 5 } & $\mathrm{N}$ & $\%$ & $\mathrm{~N}$ & $\%$ \\
\hline Normal & 50 & 83 & 50 & 83 \\
Absent & 3 & 5 & 3 & 5 \\
IP I & 2 & 3 & 2 & 2 \\
IP II & 4 & 6 & 4 & 6 \\
Common cavity & 1 & 2 & 1 & 2 \\
\hline Total & 60 & 100 & 60 & 100 \\
\hline
\end{tabular}
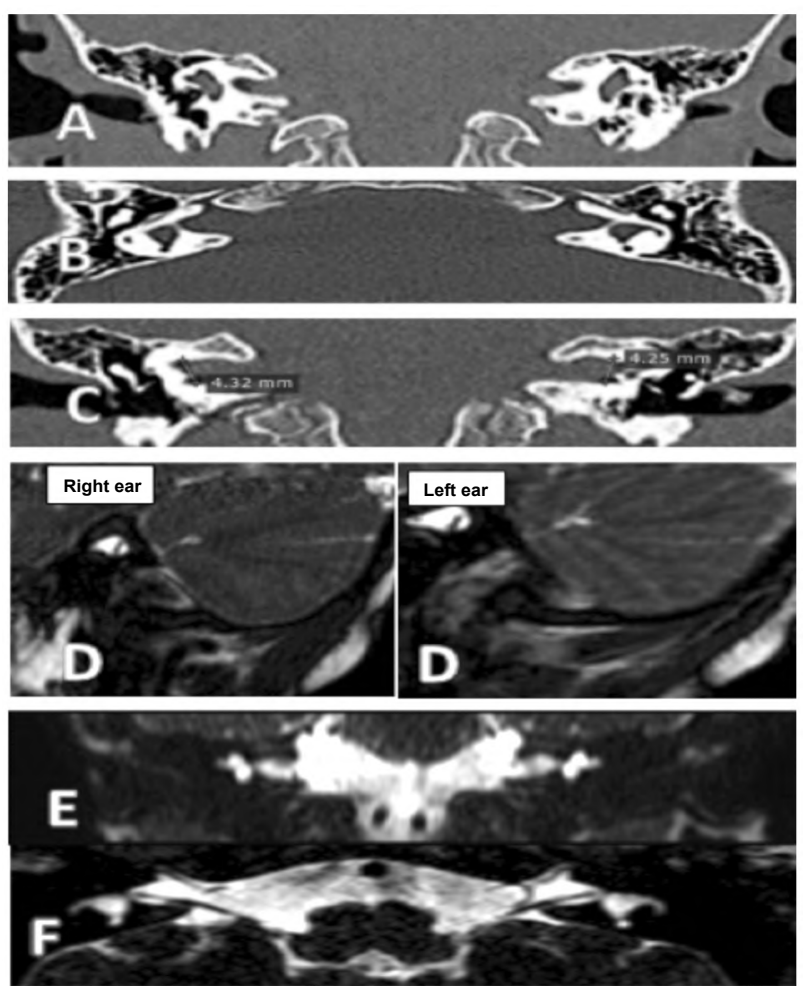

Fig. (3): A 2 years old Female patient Presented with bilateral SNHL with no history of fever. MDCT Axial, Coronal and sagittal Oblique views showed: (A,B) Bilateral complete absence of the cochlea (Cochlear aplasia). (A,B) Hypoplastic superior and posterior semicircular canals. (C) Internal auditory meatus on right side $(4.3 \mathrm{~mm})$, left side $(4.2 \mathrm{~mm})$. MRI Axial T2, Coronal T2, Sagittal oblique FFE \& 3D drive of the internal ear showed: (D) Bilateral cochlear nerve agenesis. (D,E,F) Bilateral coclear aplasia with cochlear nerve agenesis. It was Contraindicated for cochlear implantation. 

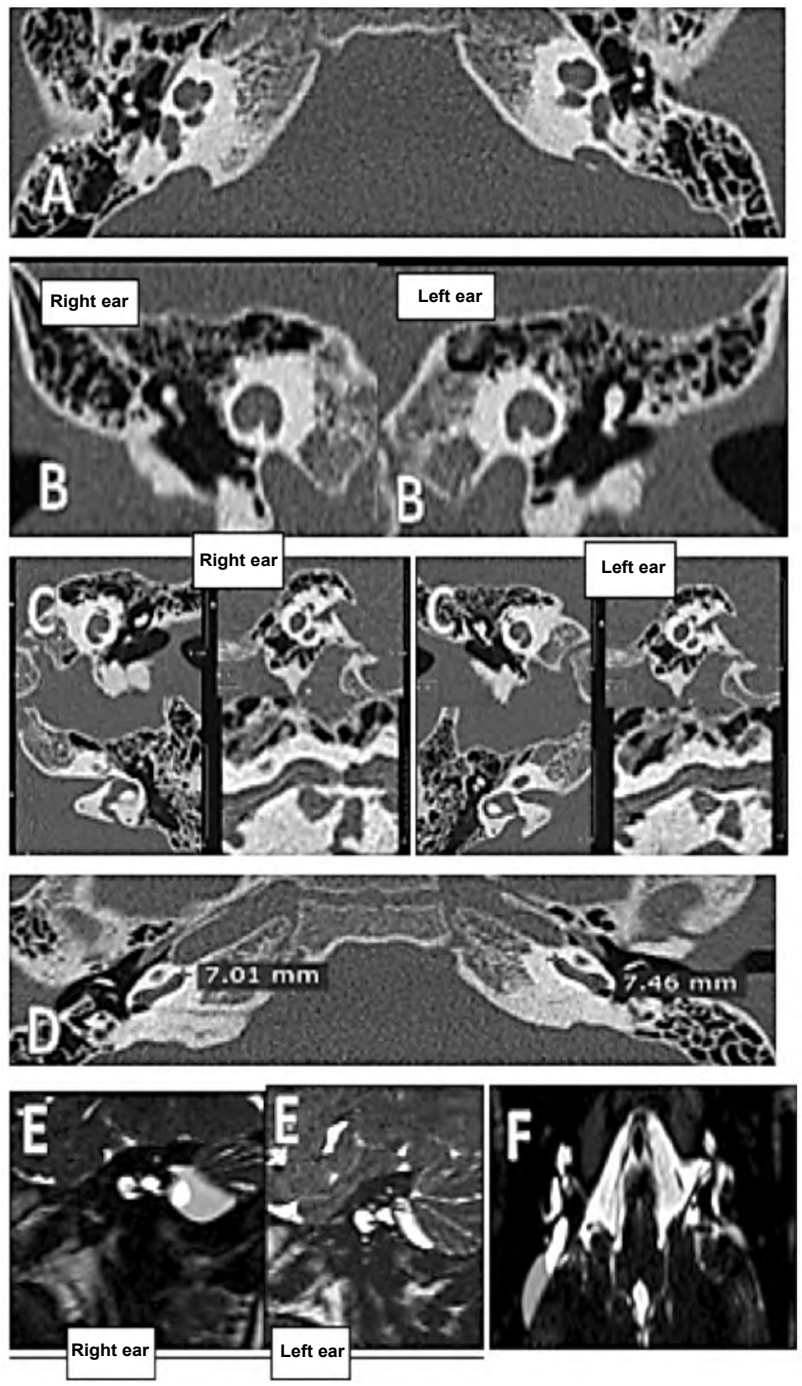

Fig. (4): A 4 years old Female patient Presented with bilateral SNHL since birth. MDCT Axial, Coronal and sagittal Oblique views showed: Bilateral vestibular acqueduct syndrome with bilateral incomplete partition of the cochlea (Modini Malformation), and bilateral endolymphatic sac diltation (A,B). Bilateral incomplete partition of the cochlea (A) Bilateral dilated vestibular acqueduct

\begin{tabular}{lcl}
\hline C, D & $\begin{array}{c}\text { Right side } \\
(\mathrm{mm})\end{array}$ & $\begin{array}{c}\text { Left side } \\
(\mathrm{mm})\end{array}$ \\
\hline Internal auditory canal & 10 & 9 \\
Basal (1 st) turn of cochlea & 7 & 7.46 \\
Whole cochlear length & 29 & 29 \\
\hline
\end{tabular}

MRI Axial T2, Coronal T2, Sagittal oblique FFE \& 3D drive of the internal ear was showing: Bilateral vestibular acqueduct syndrome with bilateral incomplete partition of the cochlea (Modini Malformation).(E) Bilateral incomplete partition of the cochlea. The basal turn is intact; the more apical turns are absent $\&$ replaced by a single cystic cavity. (F) Bilateral vestibular aqueduct syndrome with bilateral incomplete partition of the cochlea). Right endolymphatic sac dilatation.

\section{Discussion}

Cochlear implants were introduced commercially in 1972 . These devices stimulate the auditory nerve directly when placed in the cochlea (tympanic ramp) [8]. Today screening tests as part of newborn evaluations facilitate the early detection of congenital hearing impairment [9].

The surgery for the cochlear implantation is common in present era and one of the most successful surgical procedure in congenital and acquired sensorineural deep hearing loss particularly in those patients who have not responded well to medical treatment [10].

Cochlear implants are used recently in patients having hearing loss, whether congenital or acquired cause, so it is very important for the implant surgeon and for the radiologist to have detailed knowledge of the cochlear cavity, which is location for the active electrode of implant. In present time, Computed Tomography (CT) and Magnetic Resonance Imaging (MRI) used as combined modality in preoperative workup of the cochlear implant patients [11] .

As a cochlear implant surgeon and as a radiologist, it is most important to understand the imaging findings, which contraindicate the surgery like complete labyrinthine agenesis, cochlear nerve agenesis and cochlear ossification. However, the value of $\mathrm{CT}$ in the qualitative and quantitative evaluation of patients with sensorineural hearing loss has been reported earlier [12] .

Patients with bilateral congenital profound SNHL and various inner ear malformations can benefit from cochlear implant but the presence of bilateral hypoplastic vestibulocochlear nerve is considered as a contraindication to a successful surgery. In these patients, brainstem implant would be an alternative [13].

CT depicted dysplastic malformations of the inner ear structures, which have been reported earlier to be an important cause of sensorineural hearing loss, especially in pediatric age prior to speech development [14]

Casselman et al., [15] were first to apply Constructive Interference in Steady State-Threedimensional Fourier Transformation Magnetic Resonance Imaging (CISS-3DFT MRI) in the study of the inner ear and in the cerebellopontine angle.

3D images in CT and MRI provide the information to the operating surgeon with anatomical structural information, which helps in cochlear 
implantation surgery and provide information for contraindication of implantation [16].

Yi et al., (2013) [17] advised otologist in an assessment of SNHL not to hesitate to evaluate the inner ear structure by CT scan for detecting anomaly and to gain information of pathophysiology of hearing loss.

MRI and CT have become essential parts of the diagnostic work-up in patients with symptoms related to the inner ear. Both imaging modalities are complementary. The strength of CT lies in the better delineation of the osseous otic capsule. The soft-tissue components cannot be evaluated [18] .

However, CT scan does not directly show the cochlear nerve and MRI is highly recommended for obtaining complementary information and for observing the cochlear nerve if the patient is a candidate for cochlear implantation [17]

In current study, we found 4 ears with narrow IAC and absent vestibulocochlear nerve, 2 ears with narrowed IAC and atrophied small sized vestibulocochlear nerve. In all of them the assessment of VCN were done using 3D MRI.

In the present study CT failed to assess cochlear nerve in all 60 figs (120 ears) while MRI had detected 2 figs with absent cochlear nerve bilateral and atrophied cochlear nerve in one case. These results agreed with Henk et al., (2003) [14], they reported that $\mathrm{CT}$ is unable to depict variations of the neural structures; however, this is possible with 3D T2-weighted thin-section MRI. Also, we reported high association of narrowed internal auditory canal diameter and cochlear nerve anomalies.

We followed the same method as McClay et al., (2008) [13] for confirming hypoplasia or aplasia of the vestibulocochlear nerve by comparison of the width between facial nerve and vestibulocochlear nerve performed using MRI parasagittal reconstruction. The diagnosis of internal auditory canal stenosis is particularly important in making decision for cochlear implantation.

In our study, we reported six patients (12 ears) with labyrinthitis ossificans, CT detected calcification in the labrynith and MRI detected loss of normal fluid signal of the endolymph in figs of labrynthitis ossificans.

If any patchy hypointensity in perilymphatic fluid on MRI always suspects early fibrosis even with normal CT study. Cochlear fibrosis detection is important because cochlear implant surgeon decides the length of electrode array as per the normal length of the cochlear canal [19].

Silberman et al., [20] studied 40 patients with deep hearing loss. These authors suggested that fibrosis may be missed on CT scan, so using CT scan and MRI together as complement modalities as pre-operatively in cochlear implants patients is mandatory.

Henk et al., (2003) [14] proved that both MRI and CT can depict sclerosis or ossification of a dysplastic labyrinth with high agreement rates. Such patients may be suitable for cochlear implant surgery only in selected figs that do not demonstrate additional fibrotic changes.

In the present study we observed that dilated vestibular aqueduct was the common cause of SNHL which reported in 5 figs which agreed with Saliba et al., (2012) who suggested that the increased use of high resolution CT scans has revealed Enlarged Vestibular Aqueduct (EVA) to be the most commonly identified inner ear malformation in children with unknown causes of SNHL.

Normal CT study not exclude large vestibular aqueduct syndrome. These are figs where only the extraosseous part of the endolymphatic sac is enlarged which cannot be seen on CT [8] .

We reported MDCT is best for the bony labyrinth and high-field MRI for the membranous labyrinth and for the assessment of the vestibulocochlear nerve. 3D reconstruction in MDCT and high field MRI are very helpful for cochlear turns and to detect cochlear anomalies.

\section{Conclusion:}

Combined HRCT and MRI studies are mandatory for evaluation of inner ear, the radiologist must be familiar with imaging findings that absolutely contraindicate implantation (Cochlear aplasia, cochlear nerve aplasia and labyrinthine aplasia), and with those that relatively contraindicate implantation (labyrinthitis ossificans, other inner ear dysplasia) and with other findings that could significantly alter or complicate surgery (Hypoplastic mastoid process, facial nerve dehiscence, Otomastoiditis).

\section{Competing interests:}

The authors pronounce that they have no competing interests. 


\section{References}

1- LANE J.I., WARD H., WITTE R.J., et al.: 3-T imaging of the cochlear nerve and labyrinth in cochlear-implant candidates: 3D fast recovery fast spin-echo versus 3D constructive interference in the steady state techniques. AJNR Am. J. Neuroradiol., 25.1: 618-22, 2004.

2- LANE J.I., WITTE R.J., HENSON O.W., et al.: Imaging microscopy of the middle and inner ear: Part II: MR microscopy. Clin. Anat., 18.3: 409-15, 2005.

3- SCHUKNECHT H.F.: Pathology of the Ear. Boston: Harvard University Press, 35.1: 84-90, 1976.

4- WRIGHT C.G. and HUBBARD D.G.: Observations of otoconial membranes from human infants. Acta Otolaryngol., 86.5: 185-94, 1978.

5- UZUN-CORUHLU H., CURTHOYS I.S. and JONES A.S.: Attachment of the utricular and saccular maculae to the temporal bone. Hearing. Res., 233.3: 77-85, 2007.

6- Le ROUX P. and HINKS R.S.: Stabilization of echo amplitudes in FSE sequences. Magn. Reson. Med., 30.1: 183-90, 1993.

7- HENNIG J., WEIGEL M. and SCHEFFLER K.: Multiecho sequences with variable refocusing flip angles: Optimization of signal behavior using smooth transitions between pseudo steady states (TRAPS). Magn. Res. Med., 49.2: 527-35, 2003.

8- OKAMOTO K., ITO J., FURUSAWA T., et al.: MRI of enlarged endolymphatic sacs in the large vestibular aqueduct syndrome. Neuroradiology, 40.3: 167-72, 1998.

9- JOINT COMMITTEE ON INFANT HEARING, et al.: Position statement: Principles and guidelines for early hearing detection and intervention programs. Pediatrics, 120.4: 898-921, 2007.

10- HUMPHRIES T., KUSHALNAGAR P., MATHUR G., et al.: Language acquisition for deaf children: Reducing the harms of zero tolerance to the use of alternative approaches. Harm Reduction Journal, 9.1: 16, 2012.
11- SENNAROGLU, LEVENT; SARAC, SARP; ERGIN, et al.: Surgical results of cochlear implantation in malformed cochlea. Otology \& Neurotology, 27.5: 615-23, 2006.

12-MARSOT-DUPUCH K. and MEYER B.: Cochlear implant assessment: Imaging issues. European Journal of Radiology, 40.2: 119-32, 2001.

13- McCLAY J.E., BOOTH T.N., PARRY D.A., et al.: Evaluation of pediatric sensorineural hearing loss with magnetic resonance imaging. Archives of Otolaryngology-Head \& Neck Surgery, 134.9: 945-52, 2008.

14- HENK, CHRISTINE B., et al.: Value of 3D magnetic resonance imaging and high resolution computed tomography in the preoperative evaluation of children with sensorineural hearing loss. European Journal of Radiology Extra, 46.1: 26-34, 2003.

15- CASSELMAN J.W., KUHWEIDE R., DEIMLING M., et al.: Constructive interference in the steady state-3DFT MR imaging of the inner ear and cerebellopontine angle. AJNR Am. J. Neuroradiol., 14.3: 47-57, 1993.

16- H. RIC HARNSBERGER, H. CHRISTIAN DAVIDSON, RICHARD H. WIGGINS III, et al.: Diagnostic Imaging of Head and Neck, 133.7: 677-83, 2004.

17- YI J.S., LIM H.W., KANG B.C., et al.: Proportion of bony cochlear nerve canal anomalies in unilateral sensorineural hearing loss in children In, International Journal of Pediatric Otorhinolaryngology, 77.1: 530-3, 2013.

18- KROMBACH G.A., HONNEF D., WESTHOFEN M., et al.: Imaging of congenital anomalies and acquired lesions of the inner ear. European Radiology, 18.2: 319, 2008.

19- KARINO S., HAYASHI N., AOKI S., et al.: New method of using reconstructed images for assessment of patency of intracochlear spaces for cochlear implant candidates. The Laryngoscope, 114.7: 1253-8, 2004.

20- SILBERMAN B., GARABEDIAN E.N., MOATTI L., et al.: Role of modern imaging technology in the implementation of pediatric cochlear implants. Annals of Otology, Rhinology \& Laryngology, 104.1: 42-6, 1995. 


\section{الجمع بين القيمة التشخيصية لكل من التصوير المقطعى والرنين المغناطيسى زئيس

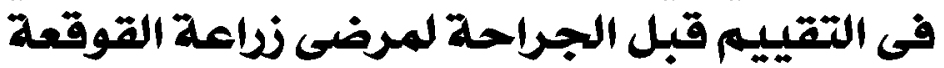

تعتبر عملية ندع القوقعة علاجاً مقبولاً به للمرضى الذين يعانون من فقدان شديد اللسمع فى حالة تواجد قوقعة الآذن العصب السمعى القوقعى سليم.

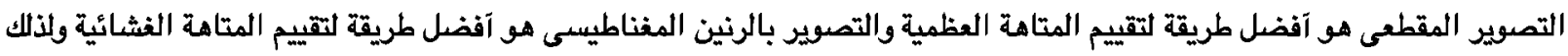
الجمع بينها ضرودى اللتقيم قبل عملية نراعة القوقعة ويجب آن يكن طبيب الآشعة متعارف على الموانع المطلقة والنسبية لعملية نراعة القوقعة.

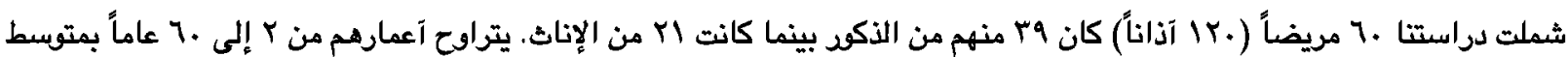

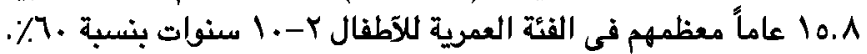

شملت الدراسة الحالية المرضى الذين يعانون من فقدان شديد للسمع الحسية عميقة، والحد الآدنى لسن الآهلية سنتان، وسيتم إدراج كلا الجنسين. إستثينا المجموعة العمرية للآطفال آقل من سنتين.

$$
\text { • تعرض جميع المرضى لما يلى: }
$$

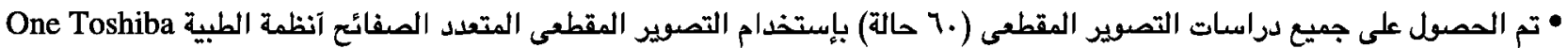
Aquilion

• تم الحصول على جميع دراسات التصوير بالرنين المغناطيسى (.7 حالة) (General Electric SIGNA) جهاز الرنين المغناطيسى المغلق

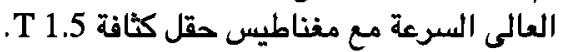

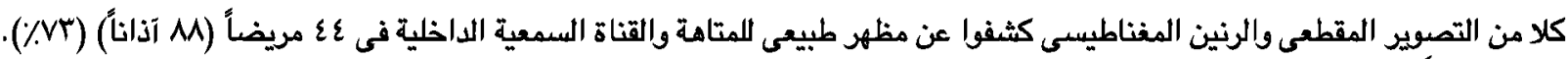

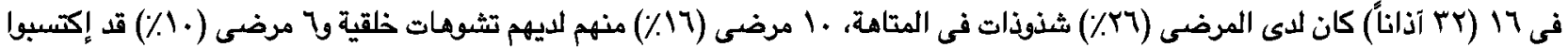

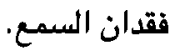

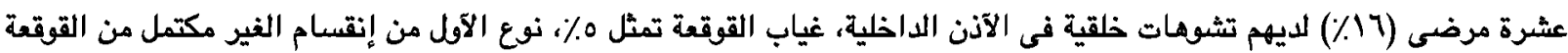

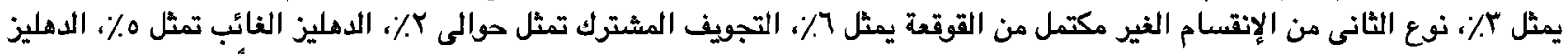

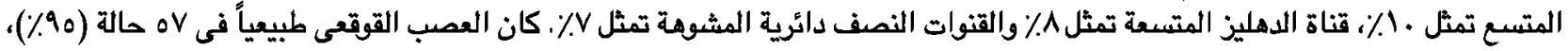

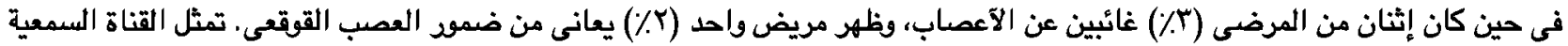

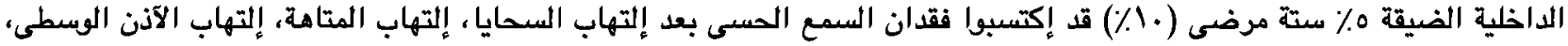

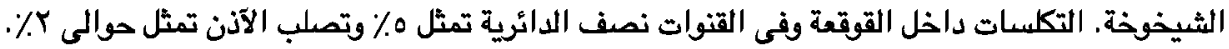

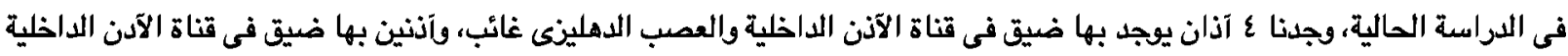

وضمود العصب الدهليزى الصغير الحجم. فى كل منهم تم تقييم العصب السمعى بإستخدام التصوير بالرنين المفناطيسى الثلاثى الآبعاد.

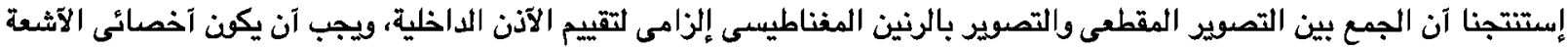

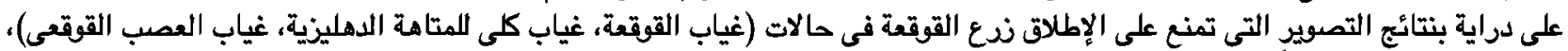

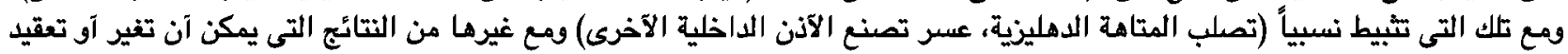

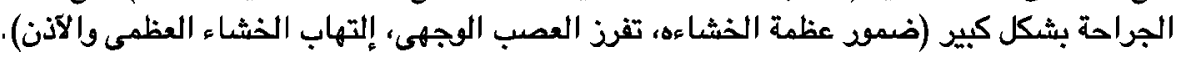

